\title{
Das vormoderne Drama als Mediendispositiv
}

\section{Das Beispiel Jacob Ayrer}

\section{Christiane Ackermann}

Zusammenfassung Schon die Vorrede zu den nachgelassenen Dramen Jacob Ayrers zeichnet ein recht genaues Bild von der dispositiven Wirkung Ayrerscher Dramatik, gleichwohl aus zeitgenössischer Perspektive und dient daher als Ausgangspunkt des vorliegenden Beitrags (1). Ayrers Dramen sind auf Lektüre angelegt - eine Lektüre, welche die Aufführungssituation mitzudenken hat und den Leser nicht nur zum Zuschauer eines imaginierten Theaterstückes macht, sondern auch zum Augenzeugen (historischen) Geschehens und Co-Produzenten von Geschichte. Die Abläufe der Projektion und Identifikation, in die der Rezipient involviert ist, lassen sich über den Begriff des >Mediendispositivs< konzeptionell fassen (2). Die Verbindung von Historie mit literarischen Elementen zum einen und kulturellen Klischees zum anderen stört diese Imagination nicht (3). Sie befördert vielmehr den immersiven Effekt des medialen Dispositivs Drama, wie das Beispiel der Machumet-Tragedia zeigen soll (4). Der Aufsatz stellt so exemplarisch die Funktionsweise des >Türkendramas< als Mediendispositiv vor, ein Dramentypus, dessen plurimediale Ästhetik an der Wende vom 16. zum 17. Jahrhundert mit Ayrer zu einem Höhepunkt gelangt.

Schlüsselwörter Mediendispositiv · Medialität · Jacob Ayrer · Theatergeschichte · Turcica · Türkendrama 


\section{The Pre-Modern Drama as a Media Dispositif}

The Example of Jacob Ayrer

Abstract The preface to Jacob Ayrer's posthumous dramas already gives a fairly accurate picture of the dispositive effect of his works, albeit from a contemporary perspective and therefore serves as the starting point for the present contribution (1). Ayrer's dramas are intended to be read - a reading that has to take their performance into consideration and makes the reader not only a spectator of an imaginary play, but also an eyewitness of (historical) events and co-producer of history. The processes of projection and identification, in which the recipient is involved, can be conceptualized by the term >media dispositive< (2). The combination of history with literary elements on the one hand and cultural clichés on the other does not disturb this imagination (3). Rather, it promotes the immersive effect of the media dispositive drama, as the example of the Machumet-Tragedia shows (4). The essay thus presents an example of how the >Turk drama< functions as a media dispositive, a type of drama whose plurimedial aesthetics reached a climax at the turn of the 16th and 17th centuries with Ayrer.

Keywords Media Dispositif · Mediality · Jacob Ayrer · History of Theatre · Turcica · Turk Drama<

\section{Das Drama als Denkmal und imaginäres Theater-Dispositiv ${ }^{1}$}

Opus Thaeatricum - die so betitelte 1618 gedruckte Sammlung der nachgelassenen Dramen Jacob Ayrers (1544-1605) sollte nach Wunsch der Herausgeber dem Dichter und seinem Werk ein Denkmal setzen - ein Denkmal, das eine seinen Stücken analoge Wirkung entfalte. ${ }^{2}$ Wie die Vorrede an den christlichen guthertzigen Leser expliziert, habe Weyland der Erbar, auff der Löblichen Schreiberey fürneme vnnd wolerfahrne Herr Jacob Ayrer der Elter, Käyserlicher Notarius, Burger vnd der Gerichten [...] zu Nürmberg geschworner Procurator in seinen Comedien vnd Tragedien zahlreiche denckwürdige fürtreffliche Römische vnd andere Hystorien vnd Geschicht zusammen getragen zu Lob, Preiß vnd Ehren von wolverdienten hohen vnd anderer fürtrefflicher Männer. Ihrem Andenken diente Ayrers Löbliche[] Poetery. ${ }^{3}$ Nun möge die Publikation seines Oeuvres zum Denkmal des Dichters selbst werden:

\footnotetext{
1 Der vorliegende Beitrag stellt zusammenfassend und am Beispiel Ayrers den Ansatz meiner Habilitationsschrift zu den vormodernen Türkendramen vor: Imago Turci. Das >Türkendrama< als medialer Brennpunkt der Vormoderne [15.-16. Jahrhundert]. Habil. masch. Tübingen 2017.

2 Der Druck erfolgte in Nürnberg durch Balthasar Scherfen, dreizehn Jahre nach Ayrers Tod, dessen Kinder, Verwandte und Freunde die Publikation seiner Werke vorbereiteten und finanzierten. Vgl. die Vorrede, in: Adelbert von Keller (Hg.): Ayrers Dramen. 5 Bde. Stuttgart 1865, Bd. 1, S. 3-8, hier S. 5 f. Die Ausgabe wird nachfolgend mit dem Kürzel AD zitiert.

3 AD 1, Titelblatt; Vorrede, S. 4f. - Jens Haustein erläutert, der in der Vorrede erklärte Zweck der Drucklegung habe gliedernden Charakter: »Der Hinweis darauf, daß das Werk der Undankbarkeit gegen die Verdienste der Potentaten begegne und lasterhaftes Handeln aus Müßiggang verhindere, zielt offenbar außer auf die Motivation für die Herausgabe des Werks auch auf die Grobgliederung des Opus thaeatricum, in dem den Herrscherdramen die Possenspiele folgen und das so der traditionellen Gattungshierarchie gerecht
} 
Dannen hero haben Ehrngedachten Authoris hinderlassene Erben beneben andern guten Freunden vnnd bekannten, denen dergleichen Hochlöbliche Kunst der Poeterey nicht wenig beliebet, solche Ayrerische Poetische concepta [...] zusammengetragen vnd endlich, ob eingangs angeregtem alten Römischen gebrauch der Statuen oder Colonen vnd Pyramiden nachzufolgen, [...] durch den Druck Publicirt (AD 1, S. 6).

Eine verlebendigende Memoria soll es sein, so wie sie Ayrer durch seine Dichtung anderen zuteilwerden ließ. Zu einem solchen Zweck tauge ein Buch mehr als große Bauwerke mit Säulengängen und Statuen, zeige doch die Vergangenheit, dass diese untergehen könnten, während die Schrifften vnd Bücher von solchem Schicksal verschont blieben:

In bedenckung dessen, das die Pyramides, Seulen vnd Büldnussen allerhand materien mit der zeit schadhafft oder durch gewalt zerbrochen werden oder wol gar verfallen, dessen man sonderlich in den Nieder-so wol andern Landen Exempla hat, das wol gantze Städt versuncken, vntergangen vnd mit Wasser bedeckt seien, da hergegen die Schrifften vnd Bücher dergleichen vntergang befreyet, dann was jrgendt in einem Landt oder Ort ab vnd vntergehet, das findet man in vielen andern vnd vnzehlichen orten vnschwer wider, also das, Menschlicher weif davon zu reden, nichts Tauerhaffters vnd vnsterblichers ist, als eben die Bücher, die lassen sich nimmermehr außrotten [...] (AD 1, S. 4).

Anders als die auf lange Sicht ephemeren architektonischen Räume und Bilder vergangener Kulturen ist das, was lob-vnd denckwürdigs in Büchern zu guten beschrieben vnnd gleichsam zu einem Schatz eingewickelt von Dauer (ebd.). ${ }^{4}$ Auf diesem Verständnis fußt die posthume Drucklegung der Ayrerschen Dramen: So

wird. Die Redaktoren waren über diese naheliegende Grobgliederung hinaus bemüht, eine sinnstiftende, die Gesamtheit des Geschichtsverlaufs und der Weltabenteuer abbildende Feingliederung zu schaffen: Der Band beginnt mit Der Tragedi. Erster Teil; von Erbauung der Statt Rom, geht dann über in die deutsche Kaisergeschichte (hier ist auch die Gründung Bambergs dramatisch verarbeitet) und wird erweitert um Episoden der griechischen und orientalischen Geschichte; die letzten Comedien leiten thematisch zu den Fastnachtspielen über, die menschliche Laster in ihren verschiedensten Formen vorführen. Den Fastnachtspielen folgen die vor allem formal innovativen Singspiele«. Ders.: »Jacob Ayrer«. In: Stephan Füssel (Hg.): Deutsche Dichter der frühen Neuzeit (1450-1600): Ihr Leben und Werk. Berlin 1993, S. 575-588, hier S. 577.

${ }^{4} \mathrm{Zu}$ dem seit der Antike greifbaren »Topos von der Schriftkultur als einem monumentalem Transkriptionsmedium« und dem Buch als Denkmal des Autors vgl. Wolf-Dietrich Löhr, der »die Verbindung der Tradition sepulkraler memoria mit der bildlichen Reflexion literarischer Autorschaft « am Beispiel des Titelblatts einer in den 1460er Jahren entstandenen Petrarca-Handschrift diskutiert (ders.: »Tätige Trägheit. Petrarca, Bembo, Sanvito und das Buch als Denkmal des Autors«. In: Gerald Kapfhammer [Hg.]: $A u$ torbilder: Zur Medialität literarischer Kommunikation in Mittelalter und Früher Neuzeit. Münster 2007, S. 155-199, hier S. 155f.). Zur Reflexion des Buchs als Erinnerungsmedium des Autors in der deutschsprachigen Literatur des Mittelalters erläutert Horst Wenzel am Beispiel von Thomasins Welschem Gast: »Indem die Stimme eines Sprechers sich in der Handschrift materialisiert, wird auch das Eikon (der name) einer sprechenden Person auf das neue Medium übertragen. [...] Indem er das Buch aus der Hand gibt, das buoch seinen Herrn verlässt, beginnt es allerdings ein eigenes, vom Autor losgelöstes, ihn aber auch vervielfältigendes Leben. [...] Die Fortschreibung der Bücher, in denen die Gattung überlebt, sichert auch dem Autor das Fortleben seines >Namens〈, wenn er längst gestorben ist« (ders.: Hören und Sehen. Schrift und Bild. Kultur und Gedächtnis im Mittelalter. München 1995, S. 207). 
wie dises sein mühselig Werck dem Lob fürtrefflicher Männer diene, so soll die publizierte Sammlung an statt eines Pyramidis dem Dramenautor zu Ehren vnd ewiger löblicher gedechtnuß seines hierin gebrauchten grossen fleiß vnd vngesparten mühseligen arbeit gereichen (ebd., S. 6). Der wiederholte paratextuelle Rekurs auf historische Monumente zielt auf die Überhöhung der Dichtkunst als Medium einer lebendigen Memoria. Diese habe allein in der previlegierten Buchform Bestand, die jedem Erinnerten gerechter werde als eine Lobpreisung zu dessen Lebzeiten, selbst bei persönlicher Anwesenheit des Geehrten. Dies gilt allemal für das Opus Thaeatricum, ließen doch die versammelten Dramen dem Leser die spielenden Agenten unweigerlich vor das innere Auge treten. Deshalb seien Ayrers

[...] Comedien vnd Tragedien über vralte langverloffene, herrliche vnd woldenckwürdige Geschichten, Thaten vnd Sachen [...] nicht allein zu Lesen so anmütig vnd lieblich, das, wer darinnen anfengt, nicht wol davon lassen kan, biß er das endt vnd außgang vernommen, sondern auch alles nach dem Leben angestellt vnd dahin gerichtet, das mans (gleichsam auff die neue Englische manier vnnd art) alles Persönlich Agirn vnd Spilen kan, auch so lieblich vnd begierig den Agenten zuzusehen ist, als hette sich alles erst ferden oder heuer verloffen vnd zugetragen (AD 1, S. $5 \mathrm{f}$.).

Die Herausgeber erheben so das gedruckte Opus Thaeatricum zu einem Monument der Monumente. Sie formulieren damit nicht nur einen monumentalen Anspruch der Literatur, sondern sie umschreiben und benennen auch die ästhetische Wirkungsweise, die dem Drama als spezifisch literarischer, d.h. schriftlichpoetischer Form zukommen soll. Das historische Monument ist zuerst eine architektonisch feste Form zur Erinnerung (Pyramides), das mit seinen Säulengängen (Colonen, Seulen) einen Zugang zu den Werken der bildenden Kunst (Büldnussen allerhand materien) bietet. Diese Bildwerke sind aber als Statuen räumlich fixiert, statisch und damit vergänglich.

Dagegen ist das Drama dynamisch, und - indem es der Schrift überantwortet wird - jederzeit und von jedem zur Aufführung zu bringen. Die monumentale Wirkung der Literatur erscheint so als das Gegenstück zur Architektur: Die Literatur ist hier das Monument, welches den Bildern und ihren materien in seinen dramatischen Abteilungen, einem Säulengang gleich, Raum bietet. Diese materien sind dabei rhetorisch als der historische Stoff oder die materia zu verstehen, die der Betrachter vor seinem inneren Auge räumlich animiert und damit seiner eigenen memoria einschreibt.

Diese dramatische Bildwirkung erstreckte sich nicht zuletzt auch auf den Autor, der als Gegenstück zum Rezipienten in diesen Wirkungsmechanismus mit einbezogen ist. Denn ausdrücklich wird nicht einfach die Person Ayrers genannt, es wird, in deutlicher Differenzierung, daneben und vorrangig dem Bild des Autors oder Dichters gedacht, das durch die Literarisierung des poetischen Dramas erst entsteht. Damit entfaltet die Vorrede, was das Titelblatt in semantischer Verdichtung vorformuliert, das bereits die zentralen Stichworte des in der Vorrede explizierten Anspruchs beinhaltet (s. Abb. 1): 
Abb. 1 BSB München, 2 P.o.germ 1 [VD17 23:272224X], Ayrer, Jakob: Opus Thaeatricum. Nürnberg 1618, S. I. 8 (https://www.bsbmuenchen-digital.de// web/ web1094/bsb10943402/images/ index.html?id=10943402\& fip $=$ qrssdaseayasdaseneayaeay afsdrxdsydfsdr \&no $=5 \&$ seite $=7$ [letzter Zugriff: 10.05.20])

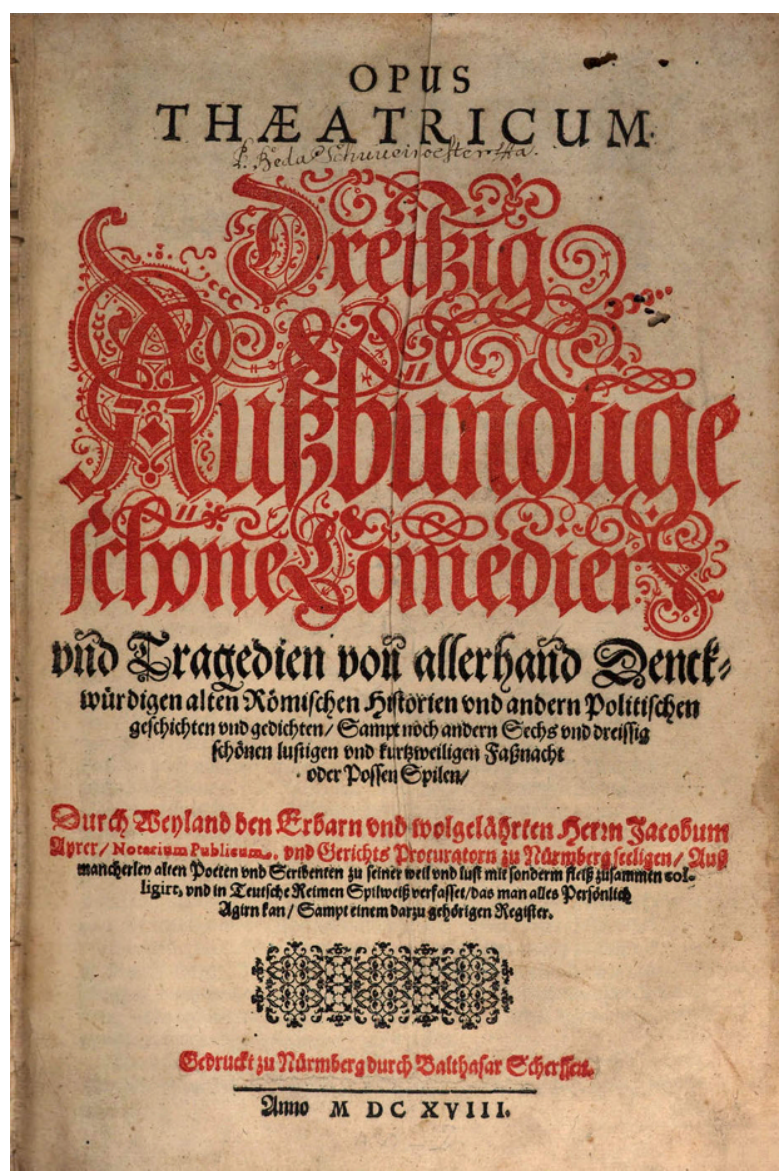

Opus | ThAEatricum | Dreissig | Aussbündtige | schöne Comedien | vnd Tragedien vonn allerhand Denck $=1$ würdigen alten Römischen Historien vnd andern Politischen I geschichten vnd gedichten/Sampt noch andern Sechs vnd dreissig I schönen vnd lustigen vnd kurtzweiligen Faßnacht I oder Possen Spilen/ I Durch Weyland den Erbarn vnd wolgelährten Herrn Jacobum I Ayrer/ Notarium Publicum vnd Gerichts Procuratorn zu Nurmberg seeligen/ Auß I mancherley alten Poeten vnd Scribenten zu seiner weil vnd lust mit sonderem fleiß zusammen col- I igirt, vnd in Teutsche Reimen Spilweiß verfasset/ das man alles Persónlich I Agirn kan/ Sampt einem darzu gehórigen Register. I Gedruckt zu Nürmberg durch Balthasar Scherffen. I Anno MDCXVIII.

Schon das Titelblatt evoziert in seinem monumentalen Schriftbild die Vorstellung aufgeführter Dramen mit dem Versprechen, die Texte seien so verfasst, das man alles Persónlich Agirn kan. Gewiss bedeutet >persönlich< hier >mit Personen<, das >persönliche Agieren< aber zielt auf den gedanklichen Nachvollzug einer Aufführung, 
die Imagination des Textes als inszenierten Schauspiels, zu dem Ayrers dramatische Texte anleiten. ${ }^{5}$ Eben dieses Qualitätsversprechen expliziert die dispositive Wirkung der Ayrerschen Stücke als Dramen, deren Lektüre, so die Implikation, einer theatralen Aufführung in nichts nachsteht, macht sie doch eine solche präsent und geht dabei noch über die Repräsentation von Geschehen (im narratologischen Sinne) hinaus: Das dramatisch Dargestellte wirke wie just stattgefunden, so als habe sich alles gerade erst zugetragen. ${ }^{6}$ Das heißt: In der Lektüre wird über die Aufführungsimagination das Geschehen selbst gegenwärtig. ${ }^{7}$ Dem historischen Anspruch von Architektur und Bildender Kunst aber ist sie damit sogar überlegen. Denn während dieser historische Anspruch durch seine Fixierung vergeht, bleibt die Geschichte in der dramatischen Form der Literatur lebendige Gegenwart.

\section{Drama und Theater als mediale Dispositive}

Tatsächlich sind Ayrers Dramen auf Lektüre angelegt, da sie insbesondere ohne die ausführlichen Regieanweisungen, die zentrale Informationen zu den Sprechern enthalten (Namen der Figuren etc.), unverstanden blieben. Die dispositive Wirkung der Dramen hängt nämlich sehr deutlich von diesen Nebentexten ab. So geben die Regieanmerkungen in Ayrers Machumet-Drama Hinweise, die sich darstellerisch gar

\footnotetext{
${ }^{5}$ Zugespitzt könnte man sagen, dass sich hier im Grunde ein früher Effekt der Literatur verdoppelt, den Manfred Kern als »imaginative Theatralität« bezeichnet hat und damit schon die dispositive Wirkung eines gelesenen oder gehörten Textes beschreibt, die »eine Rezeption des Textes als Schau « evoziert (ders: »Einleitung «. In: Ders. (Hg.): Imaginative Theatralität. Szenische Verfahren und kulturelle Potenziale in mittelalterlicher Dichtung, Kunst und Historiographie. Heidelberg 2013, S. 1-20, hier S. 8). Umgekehrt kann sich an der Instrumentalisierung der Begriffe >Theater $<$ und >Theatralität< für die Analyse mittelalterlicher Literatur aber auch die dispositive Wirkung des Mediums Theater auf die moderne Literaturinterpretation zeigen (vgl. dazu Bleumer, Hartmut: »Dramatische Dispositive. Zum Ort des Spiels vor der Zeit des Theaters. Im vorliegenden Heft, https://doi.org/10.1007/s41244-020-00173-0).

${ }^{6}$ Dass sich das Opus Thaeatricum an ein Lesepublikum richtet, geht mehrfach aus den Paratexten hervor, so auch aus dem gereimten Ad Emptorem: DEr Erbar vnd wolgeübt Herr, / Wie auch Sinnreich, Jacob Ayrer, / [...] Ist auch ein guter Poet gewest, / Der seine Scripta vnd Gedicht / All auff ein bsondere Art gericht, / Kurtz, Gut, Anmutig vnd Außbündig, / Wie auß diesem sein Werck ist kündig, / Welchs seinen Meister Lobt vnd Preist, / Als der sich darinn hat befleist, / Die Traurig-Langweiligen Gmüter / Durch kurtzweil zu erquicken wider, / Der gstallt, wer drinn hat gfangen an / Zu lesen, fast nicht auffhören kan [...] (AD 1, S. 15, V. 2-17). Die hier verfolgte Argumentation spricht nicht dagegen, dass Ayrers Dramen auch aufgeführt worden sind. Ob und in welchem Rahmen Aufführungen stattgefunden haben könnten, wird in der Forschung diskutiert. Dirk Niefanger fasst die verschiedenen Argumente zusammen und konzediert: »Ob Ayrers Dramen aufgeführt wurden oder nur Lesedramen waren, bleibt ein Streitfall der Forschung. [...] Ich denke, dass niemand 100 Dramen schreibt, ohne an eine mögliche Aufführung zu denken. Sie könnte ja auch nicht-öffentlich realisiert worden sein. Das würde dann die fehlenden Ratsersuche für öffentliche Aufführungen erklären. Dass es von Jacob Ayrer auch nach seinem Tod noch ausgesprochene Leseausgaben gab, zeigt das Doppeldrama Die Buhlerische Gesellschafft«. Ders.: »Jacob Ayrer als NichtAristoteliker«. In: Morgen-Glantz 26 (2016), S. 103-119, S. 111.

7 Vgl. auch Niefangers Diskussion der Vorrede, die die Gegenstände der Dramen als »geschichtlich überlieferte Handlungen « verstehe und sie als » gegenwärtig < - durchaus im Sinne Szondis - präsentiert « (ebd., S. 112).
} 
nicht umsetzen ließen. ${ }^{8}$ Gleich zu Beginn heißt es: Machumet, der Türckisch Keiser [...] ist noch jung von 21 Jahrn (AD 2, S. 738,16-18). Die Information über das Lebensalter ist aufführungspraktisch nicht realisierbar, aber als Erzählerkommentar verständlich. Sie zielt damit auf die Imagination eines Lesers. ${ }^{9}$ Vor allem aber wird die Orientierung über die Figurenkonstellation konsequent von den Nebentexten gesteuert und ist damit nur in der Lektüre vollständig möglich. Fast sämtliche Namen der 27 Figuren sind in den Nebentexten enthalten, im Haupttext des Dramas werden sie dagegen nur in besonderen Ausnahmefällen genannt. Im Machumet-Drama sind dies - abgesehen von zwei beklagenswerten Kindern, die, kaum dass sie benannt wurden, auch schon ein grausames Schicksal erleiden (AD 2, S. 762,21 u. 34) - bezeichnender Weise die Namen des Tricksters Jahn (AD 2, S. 776,3; 798,35; 803,33) und der des Ratgebers Mustapha (AD 2, S. 801,10 u. 16), der den Umschwung der Handlung am Ende herbeiführt.

Es hat also System, dass sich der Haupttext ohne die wörtliche Kenntnis der Nebentexte nur undeutlich nachvollziehen lässt. Die Regieanweisungen liegen auf der gleichen Ebene wie der sogenannte Haupttext. ${ }^{10}$ Erst in ihrer Kopräsenz erfüllen beide Textarten ihre imaginative Funktion. Und dieser Befund lässt sich verallgemeinern. Ayrers Dramen sind von vornherein als imaginäres Theater angelegt, die Aufführungssituation ist in der Lektüre mitzudenken. Seine Herausgeber hatten insofern eine genaue Vorstellung von der Anlage seiner Texte und ihrer dispositiven Wirkung.

Der Anspruch an die Leserschaft, den Theatercharakter in der Lektüre stets mitzudenken, setzt das Verständnis für eine Aufführung voraus. So selbstverständlich dies erscheinen mag, gilt es doch zu bedenken, dass der Text damit den Leser als

\footnotetext{
8 Ayrer, Jacob: »Schröckliche Tragedi. Vom Regiment vnnd schändlichen Sterben des türckischen Keisers Machumetis des andern dis Namens, wie er Constantinopel eingenommen vnd gantz grausam tyrannisirt, mit 27 Personen, hat fünff Actus«. In: AD 2, S. 737-809.

9 Für eine mögliche Klassifizierung der Regieanmerkungen in Ayrers Dramen vgl. Grafetstätter, Andrea: Ludus compleator: Theatralisierungsstrategien epischer Stoffe im spätmittelalterlichen und frühneuzeitlichen Spiel. Wiesbaden 2013, S. 313-316. Sie nennt u.a. Beispiele für Anmerkungen, die »konkrete dramaturgische Erfordernisse berücksichtigen«, »Regisseurhilfen« beinhalten, auf Alterungsprozesse oder Charaktereigenschaften hinweisen oder den Plot schildern (ebd., S. 33 f.). Constanze Baum dient Ayrer als Ausgangspunkt für die Diskussion des Nebentextes im frühneuzeitlichen Drama, der »an die Stelle einer Gestaltung der Handlung durch die üblicherweise im Drama dominante Figurenrede« rücke und »zur dramatischen Modellierung « von Handlung genutzt werden kann: »Das aktionsreiche Handlungsgeschehen vermittelt sich somit an dieser neuralgischen Stelle allein durch das nebentextliche Narrativ, das aus einem syntaktisch komplexen Satz mit konjunktivischen Einschüben in indirekter Rede besteht «. Anhand verschiedener Beispiele arbeitet Baum Formen »intra- und extraperformativ angelegte[r] Nebentexte[] « heraus. Dies.: »Nebentexte als Bedeutungsträger im Drama der Frühen Neuzeit«. In: LiLi 48 (2018), S. 445-461, hier S. 446, 461.

10 Für eine kritische Diskussion der Klassifizierung >Haupt- und Nebentext< des Dramas vgl. zuletzt die Beiträge des von Lily Tonger-Erk und Niels Werber herausgegebenen LiLi-Heftes Hauptsache Nebentext. Regiebemerkungen im Drama (= LiLi 68 [2018], s. Anm. 9). Programmatisch heben die Herausgeber den Stellenwert des sogenannten Nebentextes hervor »als ein elementarer Bestandteil des dramatischen Textes, der unverzichtbare rahmende, erzählende, kommentierende, strukturierende und illusionsbildende (oder auch -zerstörende) Funktionen im Drama übernimmt « (dies.: »Nebensächlich? Vorwort zum Nebentext«. In: ebd., S. 411-419, hier S. 411f.).
} 
Subjekt bestimmt, der insofern $>$ geäußertes Subjekt ${ }^{11}$ ist. Eben hier setzt der dem vorliegenden Beitrag zugrundeliegende Begriff des >Mediendispositivs< an. Er findet in Anlehnung an Jean-Louis Baudrys Überlegungen zum Dispositiv und ihre literaturwissenschaftliche Rezeption nach Jörg Dünne und Kirsten Kramer Verwendung und meint jene komplexe Struktur, ${ }^{12}$ die sich aus den Darstellungsmöglichkeiten und -bedingungen sowie den Rezeptionsmodalitäten eines Mediums ergibt und die den Ablauf bestimmt, in den der Rezipient qua Identifikation und Projektion eingebunden ist. ${ }^{13}$ Für diese Vorgänge sind - dies zeichnet sich mitunter schon im oben beschriebenen Anspruch an das Ayrersche Publikum ab - vier Aspekten zentral:

1. Narrative Wirksamkeit: Der Begriff > Dispositiv< bezieht sich nicht nur auf das medial konkret Dargestellte, sondern gerade auch auf die mit der Darstellung aufgerufenen semantischen Konnotationen. Für das Türkendrama ist dies aufgrund seines Umgangs mit den semantisch stark aufgeladenen Typisierungen der Türkenfigur in besonderer Weise relevant. Diese Typisierungen gezielt einsetzend wird das Drama narrativ wirksam.

2. Mentale Beteiligung der Rezipienten: Der Begriff des >Dispositivs < zielt auf die mentale Beteiligung des Publikums, das in die Bedeutungskonstitution des rezipierten Mediums involviert ist. Dieses macht dem Rezipienten gewisse Identifikationsangebote, nimmt er diese an, wird er Teil des Dispositivs. Durch diesen Eintritt in das Dispositiv werden für den Rezipienten eine Reihe von begrifflichen Vorentscheidungen getroffen, die darüber bestimmen, was er/sie sieht. Hierzu ge-

11 Zum Begriff vgl. Benveniste, Émile: Probleme der allgemeinen Sprachwissenschaft. München 1974, bes. S. 260-262, 281 f. u. 293.

12 Jörg Dünne und Kirsten Kramer fokussieren die spezifische Medialität des Dramas respektive Theaters. Primär verfolgen sie »das Ziel, die Kategorien >Theatralität< und >Räumlichkeit< aus theoretischer Perspektive in einen übergreifenden medienkulturwissenschaftlichen Untersuchungshorizont zu rücken«. Sie diskutieren einleitend »den Zusammenhang von Theatralität und Medialität« und »[benennen] die einzelnen Elemente bzw. relationalen Strukturen des theatralen Mediendispositivs [...], da dieses gleichermaßen den Bezugsrahmen für die Räumlichkeit des Theaters wie auch für die spezifische Theatralität jener Räume abgibt, die sich außerhalb einer konkreten Bühnen- oder Aufführungssituation (z. B. in technischen Medien wie dem Film oder der Computerkunst) konstituieren«. Die Autoren nehmen (insbesondere im Rekurs auf die Arbeiten Fischer-Lichtes) vier Aspekte in den Blick, die eine Beschreibung der »konkreten Erscheinungsformen und historischen Funktionen von Theatralität, aus denen die spezifische Räumlichkeit des Theaters abzuleiten ist«, ermöglichen: 1. Inszenierung; 2. Körperlichkeit/Verkörperung; 3. Wahrnehmung; 4. Performanz (dies.: »Einleitung. Theatralität und Räumlichkeit«. In: Dies./Sabine Friedrich (Hg.): Theatralität und Räumlichkeit. Raumordnungen und Raumpraktiken im theatralen Mediendispositiv. Würzburg 2009, S. 15-34, hier S. 15f.).

13 Baudry, Jean-Louis: »Ideologische Effekte erzeugt vom Basisapparat«. In: Eikon. Internationale Zeitschrift für Photographie und Medienkunst 5 (1993), S. 36-43 (»Effets idéologiques produits par l'appareil de base« 1970); ders.: »Das Dispositiv. Metapsychologische Betrachtungen des Realitätseindrucks«. In: Psyche 48.11 (1994), S. 1047-1074 (»Le dispositif: approches métapsychologiques de l'impression de réalité« 1975). Zur theoretischen Verortung Baudrys vgl. Paech, Joachim: »Überlegungen zum Dispositiv als Theorie medialer Topik«. In: MEDIENwissenschaft: Rezensionen/Reviews 14.4 (1997), S. 400-420, hier S. $401 \mathrm{f}$. Einen Überblick über verschiedene mediale Dispositive bietet Hickethier, Knut: Einführung in die Medienwissenschaft. 2. aktualisierte und überarbeitete Aufl. Stuttgart/Weimar 2010, S. 186-200. Einleitend zu den medienwissenschaftlichen Dispositiv-Theorien Ritzer, Ivo/Schulze, Peter W.: »Einleitung «. In: Dies. (Hg.): Mediale Dispositive. Wiesbaden 2018, S. 3-24. Für eine historische Tiefenschärfe der »Metapher des Dispositivs « plädiert Bleumer (s. Anm. 5), https://doi.org/10.1007/s41244-020-001730 . 
hören beispielsweise zeittypische Argumente der anti-osmanischen Propaganda, welche die Rezipienten - etwa aus verbreiteten Türkenliedern oder -predigten kennen konnten. Dieses Wissen, respektive der mit den Typisierungen verbundene Bildervorrat wird in der Rezeption aufgerufen. Damit ist ein Prozess der Identifikation und Projektion in Gang gesetzt, d. h.: das Dispositiv ist aktiviert. Im Grunde befindet sich der Mensch beständig innerhalb dispositiver Strukturen, denn auch in der Alltagskommunikation greifen solche Mechanismen. In der medialen Rezeption kommen aber zusätzliche Aspekte hinzu und zwar abhängig von der Art des Mediums.

3. Der Rezipient als >gesprochenes< Subjekt: Während in einer Alltagskonversation eine Person durch ihre sprachlichen Äußerungen unweigerlich mentale Bilder produziert, mit denen sie sich positiv oder negativ identifiziert, und für sich im Verhältnis zum Formulierten eine Position im Verhältnis zum Kommunikationspartner formuliert, werden diese Vorgänge in der (ggf. imaginären) Theaterrezeption zunächst vom medialen Dispositiv übernommen. Das rezipierende Subjekt spricht nicht selbst, sondern wird vom Medium >gesprochen $<$, das die Vorstellungsbilder und damit verbundene Axiologien gleich mitliefert. Dazu dienen u.a. Personalpronomina (>wir als Glaubensgemeinschaft $<$ ) oder Deiktika ( hier $<$; >dort $<$ ). Das Drama, respektive Theater formliert insofern für den Rezipienten eine Subjektposition, aufgrund derer er an das kommunizierte Geschehen mental anschließen kann. In der Theateraufführung geschieht dies beispielsweise dadurch, dass der das Stück eröffnende Proklamator das Publikum direkt anspricht, sich und die Rezipienten zu einer Wertegemeinschaft zusammenbindet (z. B. durch das Pronomen >wir $<$ ) und von einem Gegenüber graduell variierend abgrenzt, das eine eigene, Differenz markierende Bezeichnung erhält (z. B. >ihr $<$; >die Türken<). Dieser Mechanismus, in dem der Rezipient vom Medium > gesprochen $<$ wird, ist der des Dispositivs. Vom Medium geht also eine $>$ Anrufung $<{ }^{14}$ aus, die eine imaginäre und symbolische Dimension hat: Wenn sich der Rezipient als angesprochenes Subjekt mit dem geäußerten Subjekt (= imaginär) identifiziert, nimmt er seine Position in der Syntax des geäußerten Satzes ein (= symbolisch). Allein das konstituiert die subjektive Position. Eine Individualität ist damit also nicht gemeint.

4. Imaginärer Entwurf der Sinnhaftigkeit von Welt: Zwar werden die Bilder, die das Theater den Zuschauern zur Identifikation anbietet (d.h. zur mentalen Aufnahme, Verarbeitung und Einordnung in das vorhandene Welt- und Selbstbild), zunächst auf der Bühne hergestellt. Gleichwohl kann die Identifikation nur durch ein gewisses Vorwissen gelingen (vgl. Punkt 2), wenn der Rezipient an bestimmte Inhalte, etwa Glaubensinhalte, anzuschließen und sich in die Bedeutungszusammenhänge hineinzudenken vermag. Ab diesem Moment aber ist er Teil des Dispositivs als sinnstiftendem Mechanismus. Ein ganz zentrales Charakteristikum der Türkendramen ist, dass sie vorgeprägte Vorstellungen über die >eigene < und die >andere < Welt bedienen und sie axiologisch einbetten, dann aber in eine eigene Form bringen. Das Publikum kann über die ihm vertrauten Bilder und Werte an das Gezeigte gedanklich anschließen und Neues aufnehmen. Durch den Transfer und die Trans-

14 Begriff nach Althusser, Louis: Ideologie und ideologische Staatsapparate. Ansätze zur marxistischen Theorie. Hamburg/Berlin 1977, S. 142-148. 
formationen der kultursemiotischen Bilder können gesellschaftliche Normen und Glaubensgewissheiten als solche vermittelt und gefestigt sowie Irritationen in der eigenen Lebenswelt ausgeglichen werden. Die Möglichkeit, an bekannte Inhalte anzuknüpfen und solchermaßen an ihrem Transfer und ihrer Transformation zu partizipieren, lässt die Welt als sinnhaft erscheinen.

All dies, also die Vorgänge im Rahmen des medialen Dispositivs Drama, respektive Theater, erfordert vom Publikum kognitive Leistungen, die Aktivierung von Wissen, die Realisierung von Ordnungsmustern und deren (Rück-)Projektion auf die eigene Lebenswelt.

Gegenüber dem gegenwärtig oft anklingenden, diskurstheoretischen DispositivVerständnis hat die vorgestellte medientheoretische Begriffsvariante den Vorteil, dass sie beanspruchen kann, ein handhabbarer Begriff zu sein. Die an Foucault angelehnte Auffassung des Dispositivs führt, auch weil sie aus einem rein abstrakten Textverständnis heraus gestellt wird, immer wieder zu der Frage, was man denn überhaupt unter einem Dispositiv zu verstehen habe. Damit zeigt sich gerade auch anhand dieses Rahmenkonzeptes der für die Diskurstheorie charakteristische Zug, sich einem traditionellen Fixierungsversuch zu entziehen. ${ }^{15}$

Dagegen macht der hier medientheoretisch verwendete Begriff gerade durch den zusätzlichen medialen Konzeptwechsel zwischen Drama und Theater auch jene Dialektik zwischen Diskurs und Dispositiv anschaulich, die rein texttheoretisch so verwickelt erscheint. Unterscheidet man also zunächst zwischen dem Drama als textgebundener Form und dem Theater als institutionellem, nicht weniger geformtem Ort seiner Aufführung, nimmt man dann den Begriff des Mediums mit seiner prinzipiellen performativen Dynamik hinzu, dann ist das mediale Dispositiv darüber zu bestimmen, dass die Form des Theaters als mediales Dispositiv des Dramas, umgekehrt aber auch die Form des Dramas als mediales Dispositiv des Theaters wirksam werden kann. Das mediale Dispositiv bildet dabei jeweils den Vorstellungsrahmen, der darüber entscheidet, welche semantischen Valenzen des Textes oder der dargestellten Handlung und ihrer Bilder Gültigkeit erlangen.

Aus den bisher gewählten Begriffen ergibt sich darüber hinaus, dass sich die medialen Dispositive von Drama und Theater durch Transfer und Transformation gegenseitig beeinflussen: In der medialen Transformation des dramatischen Textes im Rahmen des Theaters wird das Dispositiv Theater ebenso imaginativ mitgestaltet, wie umgekehrt der Dramentext bei einer Lektüre in seinem Dispositiv durch die Vorstellung einer (wie auch immer gearteten) Bühne mit beeinflusst wird. D.h. das Medium der Schrift, seine graphische Struktur und bildliche Ausgestaltung beeinflusst nicht nur das mediale Dispositiv Drama, sondern darüber vermittelt auch das des Theaters, wie umgekehrt auch das Medium des Theaters mit seiner konkreten

\footnotetext{
15 Foucault verwendet den Begriff >Dispositiv < in verschiedenen Schriften. Eine konkrete Erläuterung bietet er im Rahmen eines akademischen Gesprächs im Nachgang zum Erscheinen von Sexualität und Wahrheit I: Der Wille zum Wissen (1978), dessen deutsche Übersetzung noch im selben Jahr erschien: Ders.: »Ein Spiel mit der Psychoanalyse«. In: Ders. (Hg.): Dispositive der Macht. Über Sexualität, Wissen und Wahrheit. Berlin 1978, S. 118-176, hier S. 119-124.
} 
Bühnenrahmung, -struktur und Figürlichkeit den Vorstellungsrahmen des dramatischen Textes bei der Lektüre.

\section{Historische Quellen und Imago Turci auf der imaginären Bühne}

Ayrers Stücke sind darauf angelegt, die Rezipienten zu Augenzeugen historischen Geschehens und potentiellen Bürgen medial kommunizierter Geschichte zu machen, um sie in die Wirklichkeit des Dramas hineinzuziehen. Dabei gehört es zu Ayrers Darstellung woldenckwürdige[r] Geschichten, Thaten vnd Sachen (AD 1, S. 6, 1 f.), historische Quellen in seine Stücke einzubinden. Im Blick darauf ist zu bedenken, dass er sich nicht nur als Dramen-Autor, sondern auch als Historiker betätigte, setzt doch seine Auffassung von Literatur insofern auf einer anderen Ebene an.

Betrachtet man zunächst Ayrer selbst historisch, dann lassen sich zu seiner Person, seinem Leben und seinem Bildungshintergrund nur wenig gesicherte Daten zusammentragen. Nachweislich gehörte er ursprünglich dem Nürnberger Handwerkerstand an. Er siedelte 1570 nach Bamberg über und bildete sich zum Gerichtsprokurator weiter. Im Jahr 1593 kehrte er nach Nürnberg zurück, wo er als kaiserlicher Notar und Prokurator am Stadtgericht tätig war.

Erst jenseits dieser historischen Existenz, als Autor hat er deutlichere Spuren hinterlassen. Ayrer ist Verfasser zahlreicher Fastnachtspiele, Komödien, Tragödien und Singspiele. Von seinen 106 Stücken sind 69 Dramentexte erhalten, überliefert in einer 22 Werke umfassenden Handschrift und dem 1618 gedruckten Sammelband Opus Thaeatricum. Die Handschrift verzeichnet acht Tragödien, zwei Komödien und zwölf Fastnachtspiele. Die meisten dieser Stücke beinhaltet auch die gedruckte Sammlung, drei jedoch fehlen dort und sind nur in der Handschrift inkludiert. ${ }^{16}$ Adelbert von Keller nahm sie in seine Ausgabe des Opus Thaeatricum (1865) auf. Nur wenige weitere Texte Ayrers sind überliefert. Dazu zählen seine Bamberger Reimchronik (1570, 1591, 1599), ein Geschenk an Bischof Veit II. (1561-1577), deren Prosafassung (1583) und eine versifizierte Bearbeitung von Luthers Psalterübersetzung. ${ }^{17}$

Literaturhistorisch zeigt sich dazu ein charakteristischer Wandel des Autorbildes, der sich durch die Veränderung im Konzept der Literaturgeschichte ergeben hat. In der älteren Literaturgeschichtsschreibung galt Ayrer vielen kaum mehr als ein Epigone des Hans Sachs. Zwar würdigte man seine Innovationen unter Einfluss der englischen Komödianten, verwies aber zugleich auf seine Bedeutungslosigkeit für die folgende Dramenentwicklung. ${ }^{18}$ Mit dem zunehmenden Interesse an den spätmit-

16 Deutschgeschriebenes Comedi-buch. N. I. M. 4. Staatsbibliothek Dresden; Inhaltsüberblick in AD 5, S. $3423 \mathrm{f}$.

17 Vgl. Gantert, Karl Josef: Der Psalter des Jacob Ayrer. Diss. masch. Heidelberg 1924.

18 Zur Forschung vor 1900 vgl. Wodick, Wilibald: Jakob Ayrers Dramen in ihrem Verhältnis zur einheimischen Literatur und zum Schauspiel der englischen Komödianten. Halle a. S. 1912, S. 1-8, 106-113. Zu Leben und Werk Ayrers sowie seinem literaturgeschichtlichen Stellenwert nach 1900 vgl. Hampe, Theodor: Eine Porträtmedaille auf Jakob Ayrer (zugleich ein Beitrag zur Biographie des Dichters). Nürnberg 1904; Wodick (s. diese Anm.), S. 9f.; Höfer, Gottfried: Die Bildung Jakob Ayrers. Leipzig 1929; Probst, Hans: »Jakob Ayrer und Bamberg. Neues über sein Leben und seine Werke«. In: Bericht des Historischen 
telalterlichen Fastnachtspielen, ihrer Weiterentwicklung sowie der grundsätzlichen Neubewertung von Spielformen zwischen Mittelalter und Früher Neuzeit nicht zuletzt im Zuge einer kulturwissenschaftlichen Wende der Germanistik hat man sich auch Ayrer unter anderen Vorzeichen zugewandt: Der Autor wird über die Frage nach der historischen Medialität im Spannungsfeld von Bild, Schrift, Drama und Theater interessant. ${ }^{19}$

Insofern muss die von Ayrer als Autor vertretene Geschichts- und Literaturvorstellung von besonderem Interesse sein. Die Spannung, die sich hier zeigt, lässt sich werkseitig ausgehend von Ayrers Bamberger Reimchronik andeuten, welche die Grundlage für sein monumentales Bamberg-Drama bildet:

Tragedia vnd gantze Histori von Erbauung vnd Ankunft der Stadt vund Stiffts Bamberg, gantzer Regirung vnd Absterben Keiser Heinrici Secundi vnnd seiner Gemahlin Künigunda, so viel derselben Geschicht auss wahrhafften Cronicis zu beweisen ist [...] (AD 1, S. 576-735).

Aus dem Titel geht der Anspruch hervor, verbürgte Geschichte darzustellen und zwar auf der Basis wahrhaffte[r] Cronicis. In dem vermutlich ersten dramatischen Werk Ayrers ${ }^{20}$ hat auch der Türkenkrieg an der Wende zum 17. Jahrhundert Niederschlag gefunden, durch den die »Handlungsunfähigkeit der Reichsorgane ${ }^{21}$ offenkundig wurde. Vor diesem Hintergrund ist das Ziel des Bamberg-Dramas, wie Dirk

Vereins für die Pflege der Geschichte des ehemaligen Fürstbistums Bamberg 85 (1937), S. 5-27; MüllerLobeda, Hans: »Die Herkunft des Dramatikers Jakob Ayrer«. In: Mitteilungen des Vereins für Geschichte der Stadt Nürnberg 43 (1952), S. 510 f.; Sachs, Hans Günter: Die deutschen Fastnachtspiele von den Anfängen bis zu Jakob Ayrer. Diss. Tübingen 1957, S. 127-130, hier bes. S. 130; Catholy, Eckehard: Fastnachtspiel. Stuttgart 1966, S. 63; Kiesselbach, Dorothee: »Jacob Ayrer, der Nürnberger Notar, Procurator und Poet«. In: Dies./Eberhard Dünninger (Hg.): Bayerische Literaturgeschichte in ausgewählten Beispielen. Bd. 2. München 1967, S. 197-210; Bock, Hans Bertram: »Jakob Ayrer«. In: Wolfgang Buhl (Hg.): Fränkische Klassiker: Eine Literaturgeschichte in Einzeldarstellungen mit 255 Abbildungen. Nürnberg 1971, S. 279-288; Olf, Norbert: Der Wortschatz Jacob Ayrers. Göppingen 1988, S. 4-7; Haustein (s. Anm. 3), S. 575; Wuttke, Dieter: Fastnachtspiele des 15. und 16. Jahrhunderts. 6. Aufl. Stuttgart 1998, S. 360 f.; Baro, Christine: Der Narr als Joker. Figurationen und Funktionen des Narren bei Hans Sachs und Jakob Ayrer. Trier 2011, S. 32-38 (Forschungsüberblick mit Fokus auf die Narrenfigur) sowie S. 211-214; Niefanger, Dirk: Geschichtsdrama der Frühen Neuzeit 1495-1773. Tübingen 2005, S. 105, 110f.; ders. (s. Anm. 9), S. 105-109.

19 Vgl. Kleinlogel, Cornelia: Exotik - Erotik. Zur Geschichte des Türkenbildes in der deutschen Literatur der frühen Neuzeit (1453-1800). Frankfurt a. M. u. a. 1989, S. 70-96; Baro (s. Anm. 18); Ackermann, Christiane: »Dimensionen der Medialität: Die Osmanen im Rosenplütschen >Turken Vasnachtspil< sowie in den Dramen des Hans Sachs und Jakob Ayrer.« In: Klaus Ridder (Hg.): Fastnachtspiele. Weltliches Schauspiel in literarischen und kulturellen Kontexten. Tübingen 2008, S. 189-220, hier S. 216-218; Röcke, Werner: »Entgrenzung des Karnevalesken. Die Dialogisierung von Fastnachtspiel und antiker Komödie bei Hans Sachs und Jakob Ayrer«. In: Robert Sollich u. a. (Hg.): Angst vor der Zerstörung. Der Meister Künste zwischen Archiv und Erneuerung. Berlin 2008, S. 97-111; ders.: »Identitätsverlust und Kontingenzerfahrung. Die Dialogisierung von Fastnachtspiel und antiker Komödie im Werk Jakob Ayrers«. In: Ridder (diese Anm.), S. 286-298; Grafetstätter (s. Anm. 9), S. 301-354; Weitbrecht, Julia: »Vergegenwärtigung der Antike: Lucretia in der >Kaiserchronik $<$ und in den Römerdramen von Hans Sachs und Jacob Ayrer«. In: Dies./Anna Heinze/Albert Schirrmeister (Hg.): Antikes erzählen: Narrative Transformationen von Antike in Mittelalter und Früher Neuzeit. Berlin 2013, S. 243-262, hier S. 252-257; Baum (s. Anm. 9), S. 446-448, 450f., 457-459.

20 Vgl. Wodick (s. Anm. 18), S. 10.

21 Niefanger (s. Anm. 18), S. 109. 
Niefanger aufgezeigt hat, »neben der Beschreibung der historisch-politischen Konstellation, die zur Gründung der Stadt und des Bistums führten, die Erzählung eines patriotischen Prozesses: die Einigung der deutschen Herzöge und die Stabilisierung des deutschen Kaisertums «. ${ }^{22}$ Die Bedrohung durch die Türken, so demonstriert das Drama, erfordert »ein geeintes Vorgehen $\ll .{ }^{23}$ Insofern setzt Ayrer die Inszenierung einer Problematik fort, wie sie seit Beginn der Auseinandersetzung mit der osmanischen Expansion in Mitteleuropa charakteristisch ist. Doch hierbei bleibt Ayrer keineswegs stehen, wie seine innovativen Türkendramen deutlich machen. In drei seiner Stücke rückt der Türkendiskurs ins Zentrum. ${ }^{24} \mathrm{Zu}$ ihnen gehört die erwähnte Machumet-Tragedia, mit der Ayrer erneut die concordia-Thematik aufgreift, ihre Notwendigkeit hier jedoch am Verhalten der Bürger demonstriert, deren Beitrag (in Form der Türkensteuer) gefragt ist, um die Gemeinschaft vor dem Glaubensfeind zu schützen. Der Mikrokosmos individuellen Handelns ist in den Makrokosmos der großen politischen Bühne eingebettet, um richtiges Handeln im Sinne des Gemeinschaftswohls zu plausibilisieren.

Wie kein anderer Dramenautor vor ihm schöpf Ayrer aus dem Repertoire der Imago Turci, dem zu seiner Zeit etablierten Vorrat kultursemiotischer Bilder - ein Bildervorrat, der sich in neuen, ganz unterschiedlichen Textsorten im Zuge der Auseinandersetzung mit den Osmanen und ihrer militärischen Erfolge im vormodernen Europa ausprägte. In dieser Literatur, den sogenannten Turcica, zeichnet sich die Wahrnehmung von Informationen/Nachrichten etc. über die Osmanen ab. ${ }^{25}$ Sie ver-

\section{Ebd. \\ 23 Ebd.}

24 Neben der Machumet-Tragödie sind dies die Comedia vom Soldan von Babilonia (AD 3, S. 1779-1854) sowie die Comedi von dem getreuen Ramo (AD 3, S. 1855-1925). Dass Ayrer sich für die Thematik interessierte, verwundert nicht. Zum einen spielt es im Werk des von ihm rezipierten Hans Sachs eine größere Rolle (vgl. Ackermann [s. Anm. 1], S. 253-267, 278-291; dies./Nöcker, Rebekka: »Wann gantz geferlich ist die zeit. Zur Darstellung der Türken im Werk des Hans Sachs«. In: »Texte zum Sprechen bringen«. Philologie und Interpretation. Festschrift für Paul Sappler. Hg. von Christiane Ackermann/Ulrich Barton. Tübingen 2009, S. 437-464). Zum anderen war die >Türkengefahr < in der zweiten Hälfte des 15. und zum Beginn des 16. Jahrhunderts erneut besonders aktuell. Ayrer erlebte die Einführung der Türkensteuer in Bamberg 1576. Auch war der Türkendiskurs im Nürnberg der 1590er Jahren abermals virulent, denn ab 1593 standen sich habsburgische und osmanische Truppen (in Ungarn) im sogenannten >langen Türkenkrieg`gegenüber, der bis 1606 dauern sollte. In der zweiten Hälfte des 16. Jahrhunderts griffen die Osmanen in einer weiteren Expansionsphase des Osmanischen Reichs verstärkt nach Europa aus und nahmen im Zuge dessen vierzehn habsburgische Festungen in Ungarn ein. Auch diesen Krieg begleitete ein reges Aufkommen des Türkenschrifttums. Flugblätter und -schriften verbreiteten vergleichsweise rasch Informationen und Gerüchte über große Siege der Habsburger und über grausame Taten der Osmanen. Die Texte arbeiten mit den gängigen anti-osmanischen Typisierungen und hinterblenden die neueren Ereignisse mit älteren, die man bereits theologisch gedeutet hatte. Vgl. Höfert, Almut: Den Feind beschreiben. »Türkengefahr« und europäisches Wissen über das Osmanische Reich 1450-1600. Frankfurt a. M./New York 2003, S. 113 f.; Niefanger (s. Anm. 18), S. 107.

25 Die Turcica (u. a. Predigten, >Neue Zeitungen<, historiographische Schriften, Türkenlieder und sogenannte Türkenbüchlein) produzieren und perpetuieren den >Türkendiskurs « (für einen Forschungsüberblick vgl. Ackermann [s. Anm. 1, S. 24-41]). Das Drama spielt in diesem Kontext eine besondere Rolle, denn es bringt verschiedene Formen der >Türkenliteratur< auf die Bühne, die selbst schon eine eigene performative Qualität aufweisen - eine Qualität, die sich notwendig durch die dramatische Inszenierung verdoppelt. Auch »[d]ie plurale Medialität der Türkenliteratur findet in der dramatischen Form Widerhall. Diese wirkt als mediales Dispositiv und greift vorgeprägte Sinnstiftungsmuster auf, visualisiert Wissensfelder und Ordnungsräume. So stehen beispielsweise die Figuren im ludischen Raum für christlich oder isla- 
dichtet sich in den Typisierungen der Osmanen als >Türken $<$ im Sinne einer figura. ${ }^{26}$ Die Türkendramen stellen diese figura, wie sie in den verschiedenen Texten in Erscheinung tritt, auf die Bühne und verdoppeln so ihre performative Qualität. Es lässt sich folgender Basismechanismus feststellen: Als Teil des breiten literarischen Feldes der Turcica ruft das Drama nicht nur das Bild des Türken hervor, es lässt aufgrund seiner spezifischen Medialität auch die performative, inszenatorische Praxis der Kultur selbst deutlich werden. Die Dramen amalgamieren aus verschiedenen medialen Formen vorhandene Darstellungen und Verstehensmuster und kombinieren sie zu neuen Narrativen über die >eigene< und die >andere< Kultur. In der theatralen Aufführung gewinnen die Kulturinszenierungen unter Beteiligung des Publikums Realität. Ayrers Lesedramen zeigen diesbezüglich freilich eine eigene Qualität.

\section{Ayrers Machumet-Tragedia}

In Ayrers Machumet bestimmt die figura des Türken mit seiner verdichteten Semantik von Anfang an die dramatische Perspektivierung des historischen Geschehens. Zwar arbeitet das Stück mit bekannten anti-osmanischen Typisierungen, doch scheinen die historischen Quellen selbst auf die Bühne zu kommen. Ihre Einbindung ist freilich hochgradig inszenatorisch. Zu dieser Inszenierung gehört es, die Rezipienten zu Augenzeugen historischen Geschehens und potentiellen Bürgen medial kommunizierter Geschichte zu machen, um sie so in die Wirklichkeit des Dramas hineinzuziehen. Die Tragedia erscheint insofern als ein Musterfall der von den Paratexten des Opus Thaeatricum angekündigten Qualität Ayrerscher Dramatik als medialem Dispositiv.

Das Drama stellt die >Türkengefahr $<$ als Alltagserfahrung dar;27 die Ängste und Nöte der Einwohner werden vor allem anhand der beiden zentralen Figuren, der schönen Griechin Hircavena und dem Narren Jahn, veranschaulicht, die nach der Eroberung Konstantinopels in türkische Gefangenschaft geraten. Der Binnenhandlung geht die Vorstellung Machumets (i.e. Mehmeds II.) und seiner Grausamkeit voraus. Seine vorangestellte Portraitierung verdeutlicht die Gefahr für Konstantinopel und bereitet den ersten Akt vor, der den Konflikt zwischen Konstantin XI. und Papst Nikolaus V. zum Gegenstand hat: Der Papst weigert sich, Hilfe zur Verteidigung der Stadt zu entsenden, die daher den Osmanen ausgeliefert ist. Für die dramatische Handlung in Konstantinopel ist die Reaktion der Bürger auf die Maßnahmen

misch dominierte Herrschaftsgebiete, die wiederum je eigene Axiologien repräsentieren. Dem Anspruch auf Authentizität und die Behauptung von Augenzeugenschaft wiederum kann das Drama durch die ihm eigenen Möglichkeiten der Präsenzerzeugung gerecht werden« (Ackermann [s. Anm. 1], S. 110).

26 Gemeint ist eine bildliche Repräsentationsform mit einer über sich hinausweisenden Semantik. Zu der theoretischen Konzeptionalisierung der figura im Anschluss an Erich Auerbach und ihrer mediävistischen Rezeption vgl. die Beiträge in Kiening, Christian/Mertens Fleury, Katharina (Hg.): Figura. Dynamiken der Zeiten und Zeichen im Mittelalter. Würzburg 2013.

27 Hier zu verstehen als Diskursprodukt. In diesem kritischen Sinne erstmals Winfried Schulze, der die > Türkengefahr $<$ als einen Kommunikationsprozess identifiziert, durch den allen Bevölkerungsschichten die osmanische Bedrohung vermittelt wird (vgl. ders.: Reich und Türkengefahr im späten 16. Jahrhundert. Studien zu den politischen und gesellschaftlichen Auswirkungen einer äußeren Bedrohung. München 1978, S. 10). Zur Verwendung des Begriffs in der Forschung vgl. kritisch Höfert [s. Anm. 24], S. 51-53. 
der Stadtobrigkeit gegen die Türkenbedrohung zentral, besonders die Türkensteuer sowie der Aufruf zu Buße und Gebet. Die letzten beiden Akte stellen dann die Geschichte zwischen dem Sultan und der >schönen Griechin< ins Zentrum. Nach Hircavenas Gefangennahme verliebt sich der Sultan in sie und verbringt mit ihr so viel Zeit, dass Machumets Berater eine Vernachlässigung seiner Herrscherpflichten monieren. Machumet sieht sich gezwungen, sein Manneshertz (AD 2, S. 807,9)

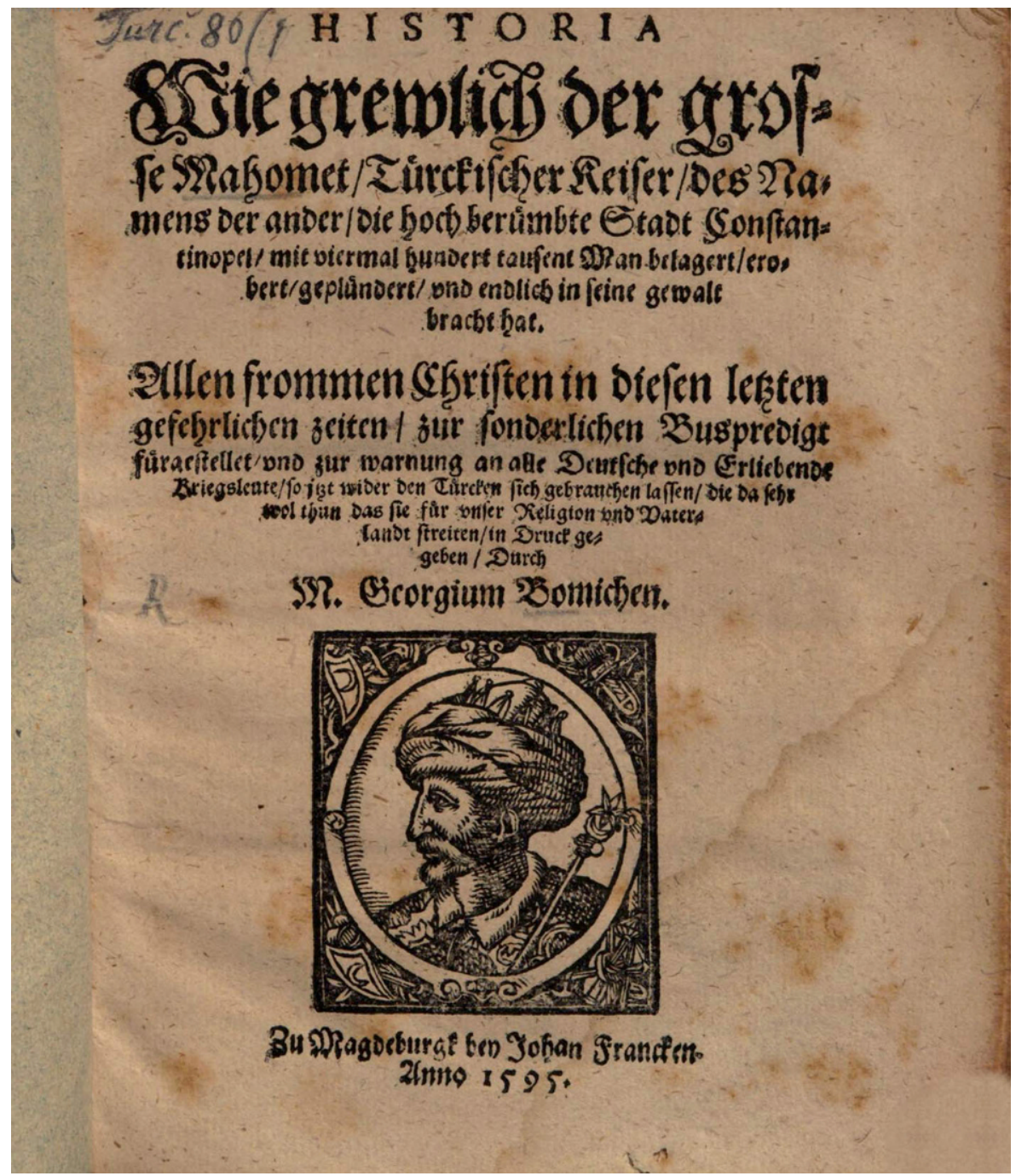

Abb. 2 Titelblatt zu Georg Bömiches Text im Druck von 1995: Historia, Wie grewlich der große Mahomet/ Turckischer Keiser/ des Namens der ander/ die hoch berumbte Stadt Constantinopel/ mit viermal hundert tausent Man belagert/ erobert/ geplundert/ vnd endlich in seine Gewalt bracht hat. Johann Francke, Magdeburg 1595 [VD16 B 6341], BSB München, Res/4 Turc. 80,1 (Digitalisat: http://mdz-nbnresolving.de/urn:nbn:de:bvb:12-bsb10204860-1 (letzter Zugriff: 10.05.20). Ein früherer Druck erschien in Wittenberg 1567 (VD16 ZV 2200)) 
unter Beweis zu stellen und säbelt Hircavena kurzerhand vor den Augen seiner Kritiker nieder. So rahmt das Bild vom grausamen Türken die Binnenhandlung von den Alltagsnöten der Bürger.

Mit diesem Aufbau greift Ayrer ein typisches Verfahren der Turcica auf: Er stellt das Portrait des türkischen Sultans voran, das er dramatisch ausgestaltet. Mit demselben Verfahren arbeitet auch Ayrers zentrale historische Quelle.

\subsection{Die Vorlagen}

In der Drameneröffnung verweist der Ehrnhold auf den Bericht Isidors über die Einnahme Konstantinopels. Gemeint ist Isidor von Kiew, der sich zur Zeit der Belagerung Konstantinopels tatsächlich dort aufhielt. Er konnte noch rechtzeitig aus der Stadt fliehen und verfasste einen Bericht, der im Druck weite Verbreitung fand. Isidors epistula de capta a Turcis Constantinopoli gehört zu Ayrers Quellen. ${ }^{28}$ Der Bericht war ihm offenbar durch die in Teilen wie üblich dialogisch arrangierte, d.h. damit bereits in gewisser Weise historisch-dramatisch wirksame Briefsammlung des späthumanistischen Juristen Nikolaus Reusner in dessen Epistolarum Turcicarum libri $V$ aus dem Jahr 1598 bekannt. ${ }^{29}$ Der Bericht war ihm offenbar durch Nikolaus Reusners Epistolarum Turciarum libri $V$ bekannt. ${ }^{30}$ Vor allem aber griff Ayrer auf einen Text des Dramatikers und populären Historikers Georg Bömiche (1567/1595) zurück (s. Abb. 2):

Auch aus Böhmiches Historia geht das Anliegen der Veranschaulichung hervor, wie schon das Titelblatt erkennen lässt: Die oben stehende Betitelung als >Historia< kategorisiert den Inhalt als wahre Begebenheit. Das Portraitbild unterhalb des Textes, das ein stilisiertes männliches Profil mit Turbankrone und orientalischer SzepterVatiante zeigt, gibt dem im Titel genannten große[n] Mahomet ein Gesicht. Die Darstelltung fasst den Gegenstand der Historia buchstäblich bildlich zusammen, ohne dass sie auch die Gräueltaten des Sultans illustriert. Dass dies nicht nötig ist, resultiert aus der etablierten figura des Türken, aus der Wirksamkeit der Imago Turci also. Im Türkendiskurs genügen einfache Versatzstücke, um dessen Inhalte, zu denen die Gräueltaten topisch gehören, aufzurufen.

Der Holzschnitt findet in verschiedenen Turcica der Zeit Verwendung. So begegnet das Sultansportrait schon auf einer Flugschrift aus dem Jahr 1593. Zwar ist eine solche Wiederverwendung ein gängiges Verfahren, hier aber im Hinblick auf die zentrale Bildwirkung der Turcica gesondert festzuhalten. Das Portrait unterstützt die auf Wiedererkennung setzende evozierte Bildlichkeit des Drucks und die Mobilisierung des imaginären Bilderreservoires auf Seiten der Rezipienten. Es ist gerade dieses für die Türkenliteratur so wichtige Vor-Augen-Stellen, das Ayrer mit seinem Machumet-Drama umsetzt.

28 Vgl. Wodick (s. Anm. 18), S. 21-26, der die Quellen des Machumet-Dramas bereits 1912 vorgestellt hat.

29 Ebd., S. 22. Vgl. Reusner, Nikolaus: Epistolarum Turcicarum variorum et diversorum authorum libri V. Frankfurt a. M. 1598, hier III, S. 104-107. Digitalisat [VD16 R 1412] zugänglich über die BSB München: https://daten.digitale-sammlungen.de/ db/0002/bsb00023934/images/ (letzter Zugriff: 10.05.20).

30 Vgl. Wodick (s. Anm. 18), S. 22. 


\subsection{Imaginäres Theater und Gegenwärtigkeit des Geschehens}

Ayrers Machumet-Drama wird vom Ehrnhold eröffnet, dessen Aufmerksamkeitsgebot die Betrachtung im Rahmen der Rezeption akzentuiert und damit den Aspekt des Vor-Augen-Stellens hervorhebt, der schon für die Vorlage so wichtig war, nun aber gemäß Ankündigung im Drama performativ umgesetzt werden soll:

Ehrnholt geht ein vnd sagt:

GÜnstig Herrn vnd züchtig Frauen,

Die jr hin seit! Heut werd jhr schauen

Eine sehr klägliche Geschicht

In ein Tragedi zugericht,

Historiweiß beschribn also

Vom Cardinal Isidoro.

(AD 2, S. 737,7-13)

Der Ehrnhold ist selbst theaterpraktische Figur und Vorbote der Präsenzerzeugung auf der Bühne. Deshalb evoziert er innerhalb des Lesedramas unmittelbar die Imagination der Theatersituation, in deren Rahmen die Ankündigung mit dem Agieren der Figuren eine performative Realisierung erführe und das Vor-Augen-Stellen Gestalt auf der Bühne gewänne. Diese Präsenzerzeugung als Effekt des medialen Dispositivs Theater aber vollzieht sich im Rahmen des Lesedramas nunmehr imaginär, unterstützt durch den Hinweis der Ehrnhold-Figur, dass die präsentierte Geschichte als Tragödie aufbereitet ist, gleichwohl Historieweiß beschrieben. Mit diesem generischen Dreischritt wird das implizierte Publikum darauf vorbereitet, dass ihm, narratologisch gesprochen, ein Geschehen (Geschicht) fiktiv (Tragedi) dargeboten wird, das über eine historisch verbürgte Geschichte vermittelt ist (Historieweiß). Auf diese Art legitimiert sich das Drama, das gattungsbedingt in Spannung zu dem formulierten Anspruch steht, historisches Geschehen darzustellen. Der Rekurs auf den Bericht Isidors ist Teil des »historischen Legitimationsgestus', der das Dargebotene fiktionaler Willkür programmatisch $\aleph^{31} \mathrm{zu}$ entheben sucht. Gestützt auf die Quelle führt der Ehrnhold die gängigsten anti-osmanischen Typisierungen an (Bäche aus Christenblut, Niedersäbeln aller Christen, Pfählung der Kinder etc.), die so zum historischen Geschehen werden. Zugleich überbietet der Ehrnhold die gängigen Topoi, denn die stereotype Kirchenschändung wird in seiner Rede zur Entweihung des Gotteshauses schlechthin, der Hagia Sophia:

Dann die schönst Kirch, so allda stand,

Zu S. Sophia ward genandt,

All Kirch in der Welt übertraff,

Darein stellt der Türck Roß vnd Schaf.

Die Altär vnd KirchenZier teur

Ließ er verbrennen als mit Feur,

Die Priester, München vnd Pfaffen

\footnotetext{
${ }^{31}$ Niefanger (s. Anm. 18), S. 110. Niefanger legt dar, dass »Ayrer zwischen erfundener und wahrer $>$ Historie « unterscheidet, auch wenn eine terminologische Einheitlichkeit nicht vorliegt« (ebd., S. 106).
} 
Vnd was mit dem Gottsdienst zu schaffen,

Ließ er gar übl martern vnd plagn,

Dem Christenkeiser den Kopff abschlagn.

In der Statt ward ein Blutvergiessn,

Daß die Bäch vol Bluts theten fissn,

Kinder, Mann, Weiber vnd Jungkfrauen

Ließ er Säbeln vnd niderhauen,

Die Kinder spist er an die Zäun,

Leget jhn an die grosse Pein,

Vil fürt er wegk mit jhm gefangn,

Thet sich an ein schöns Weibsbildt hangn,

Die het er gar lang lieb vnd werth.

Vnd als sich das Kriegsvolck beschwerd

Ob des Keisers Weiblicher That,

Er sie selbsten erwürget hat

Vor aller Herren Angesicht.

Vnd was er mehr hat außgericht,

Das werd jr sehen in diser Geschicht.

(AD 2, S. 737,20-738,15)

Die Überbietung überkommener Gräueltaten setzt sich fort mit der Behauptung, Mehmed II. habe dem Christenkeiser den Kopff abschlagen lassen. Tatsächlich sind die genauen Todesumstände Konstantins XI. Palaiologos, des letzten byzantinischen Kaisers, nicht bekannt. Angenommen wird, dass er im Verteidigungskampf gegen die Osmanen den Tod fand. ${ }^{32}$ In der Überbietung werden Christenkaiser und Hagia Sophia zu Stellvertretern für die in den Turcica ansonsten in unzähligen Varianten beschriebenen Gräueltaten. Sie symbolisieren als solche den Kern aller antiosmanischen Topoi, nämlich die Vorstellung von der vollständigen Vernichtung des Christentums. Deshalb muss Konstantin auch durch Enthauptung den Tod finden, denn der natürliche Körper des Herrschers ist zugleich ein politischer ${ }^{33}$ und insofern vermag die Trennung von Haupt und Rumpf als Auflösung einer lebendigen Einheit geradezu idealtypisch die Vernichtung des Christentums ins Bild zu setzen.

Auch die vom Ehrnhold vermerkte Grausamkeit des Sultans ist topisch, neu aber, dass sie in Verbindung mit Machumets Zuneigung zu einem bestimmten Weibsbildt gebracht wird. Das Machumet-Drama führt die historische Nachricht von der Eroberung Konstantinopels mit der >Irene<-Fabel zusammen. Das Schicksal der schönen Griechin, die in anderen Texten den Namen >Irene< (o. ä.) trägt, erscheint in der europäischen Literatur des 16. Jahrhunderts als Musterfall für die Tyrannei der Türken und ihre Lüsternheit. ${ }^{34}$ In Ayrers Version der Geschichte begehrt der Sultan die

32 Vgl. Mattejiet, Ulrich: Art. »Konstantin XI. Palaiologos (auch: K. Dragases), byzantinischer Kaiser (1449-53) (1405-1453)«. In: Lexikon des Mittelalters. Bd. 5. Stuttgart 1991, Sp. $1378 \mathrm{f}$.

33 Vgl. die grundlegende These von Kantorowicz, Ernst H.: The King's Two Bodies. A Study in Medieval Political Theology. Princeton 1957.

34 Ayrer könnte die Geschichte über ein Meisterlied (»Nun horen zue ein klegliche geschicht« [Cgm. 5102, fol. 22, Nr. 11], vgl. Wodick [s. Anm. 18], S. 26f.) oder durch englische Komödianten kennengelernt haben, die in Nürnberg ab den 1590er Jahre mehrfach auftraten und deren Einfluss sich Ayrers Einführung der 
Frau offenbar nicht nur gemäß des Klischees des begehrlichen Türken, vielmehr ist sie ihm gar lang lieb vnd werth. Dadurch gewinnt der türkische Despot in Ayrers Drama zunächst individuelle Züge, die aber sogleich wieder getilgt werden, als er unter den Verdacht > weiblicher Schwäche< gerät. Vor diesem Hintergrund kann sein tyrannisches Wesen umso eindrucksvoller herausgestellt werden, insbesondere da er die geliebte Frau eigenhändig erschlägt (selbsten erwürget), und das auch noch vor aller Herren Angesicht (AD 2, S. 738,12f.). Diese auf der Handlungsebene wichtige Augenzeugenschaft korrespondiert mit der Darstellungsebene, dank derer all das vom Ehrnhold Angekündigte den direkt adressierten Rezipienten vor Augen geführt werden soll: Das werd jr sehen in diser Geschicht (AD 2, S. 738,15). Diese Ankündigung belegt der unmittelbar folgende Auftritt des Türkischen Keisers.

So dient der Prolog - vermittelts der Figur des Ehrnholds, der Imagination seiner körperlichen Anwesenheit sowie der Inszenierung historischen Geschehens der Präsenzerzeugung im Lesedrama. Diesen Gegenwärtigkeitseffekt verstärkt die Realisierung des verbal Angekündigten mit dem ersten Auftritt des Sultans.

\subsection{Sultansportrait: Topik und Präsenzerzeugung}

Machumet erscheint nach Ausweis des Nebentextes noch vor dem ersten Akt, also direkt nach dem Auftreten des Ehrnholds und seiner Vorrede. Erst nach diesem beginnt der actus primus, d.h. nachdem das Drama die Figur des Türken in seiner Klischeehaftigkeit vorgestellt hat. Dieses Verfahren entspricht dem der Flugschriften (darunter auch Ayrers Vorlage), die dem Text ein Sultansportrait voranstellen. ${ }^{35}$ Denn so wie der Ehrnhold zunächst den Inhalt des Dramas angibt, repräsentiert der vor dem ersten Akt auftretende Sultan mit seinen Begleitern vor allem das Türkenbild, das den ganzen Text bestimmt. Ausdrücklich erklärt Machumet, er wolle sein Keiserthumb mit Blutvergiessen / Anfangen, daß ein Forcht wir machn (AD 2, S. 739,18f.). Die angekündigte Grausamkeit wird dann sofort in Handlung umgesetzt, demonstriert anhand des Brudermords und des Verlachens der trauerenden, Machumet zu Füßen fallenden Mutter, der Kaiserin Dispota. Sie führt Admurat, den Bruder des Sultans im Kindesalter, vor Machumet, dem der Knabe seine Ehrerbietung erweist:

Gnädigster Herr, Gott gebe euch

Vil Glücks vnd Heils zu eurem Reich!

Vnd weil ich noch bin jung vnd klein,

So last mich euch befohlen sein

komischen Figur Jahn verdankt. Diese Narrenfigur wurde »im 17. Jahrhundert unter verschiedenen Namen und in den unterschiedlichsten Kostümen als Hans Wurst, als Harlekin oder Pickelhering (ab 1615) zur komischen Figur schlechthin« (Röcke: »Identitätsverlust und Kontingenzerfahrung « [s. Anm. 16], S. 286). Baro hat Ayrers Narren in 34 seiner Stücke ermittelt: »Zwölf von ihnen heißen Jahn, davon tragen acht diverse Nachnamen, u. a. auch Posset. Ebenso bürgt der Name Eulenspiegel für Narrentum, aber auch ein Lörlein und ein Jodel haben sich nach eingehender Prüfung als Zugehörige zur Ayrer'schen Narrenriege erwiesen« (dies. [s. Anm. 18], S. 240).

35 Das Drama stellt diesem >Sultansportrait< das inszenierte >Konterfei< Konstantins zur Seite, der ebenfalls seinen ersten Auftritt noch vor Beginn des ersten Aktes hat. 
Vnd nembt mich auch mit Gnaden an,

Als wenn ich wer eur eigner Sohn!

(AD 2, S. 741,1-6)

Ohne dem Kind zu antworten, zieht Machumet den Säbel und haut jhn zu boden (Ad 2, S. 741, 11). Zwar war der Brudermord durch die zeitgenössische osmanische Gesetzgebung gedeckt, die Art der Inszenierung macht freilich das Unverständnis für diese Praxis überdeutlich. Zu dieser Inszenierung gehört besonders die Einführung Admurats und sein Unterwerfungsgestus verbunden mit der Bitte an den Sultan, ihn wie seinen eigenen Sohn anzunehmen. Letzeres lässt den Brudermord geradezu als Kindstötung erscheinen. Das ethische und religiöse Skandalon liegt vor allem aber auch in der Art der Tatdurchführung und dem von Hyrbris gekennzeichneten Habitus Machumets, der offenbar (wiederum topisch) im Zusammenhang mit seiner Gottesverachtung steht:

Machumet sagt:

Frau Mutter, es muß also sein,

Dann wie jhr bekennt vnd glaubt frey,

Daß ein Gott gnug im Himel sey,

Also ist es gnug auff der Erd,

Daß nur einer ein Keiser werd

Vnd man die andern all außrott.

Darumb steht auff vnd klagts eurm Gott!

Last euch jhn wider lebendig machn!

Die Keiserin schlegt die Händ zusammen vnd geht gar kläg-

lich ab. Machumet sagt:

Wir müssen der Keiserin lachn,

Daß sie nur vmb ein Hand vol Blut

So kläglich weinen vnd heüln thut,

So sie doch villeicht offt muß sehen

Wol grössers Blutvergiessen gschehen.

(AD 2, S. 741,19-34)

Spöttisch leitet Machumet seinen universalen Herrschschaftsanspruch aus der monotheistischen Religion ab. Diese desavouierend, demonstriert er, selbst nicht an Gott gebunden zu sein, was ihn (auch dies ist topisch) in die Nähe Nebukadnezars rückt. Den Glauben von sich und stattdessen seiner Mutter zuweisend (wie jhr bekennt vnd glaubt frey) unterbreitet er ihr hämisch den Vorschlag, sie möge doch ihrem Gott ihr Leid klagen und diesen bitten, den Sohn wider lebendig zu machen eine eindeutige Volte gegen den christlichen Glauben, dem Machumet die Kaiserin zuordnet. Damit wiederum scheint durch sie die Typisierung von der gequälten christlichen Frau auf und ihr erschlagener Sohn wird zum Sinnbild der von den Türken abgeschlachteten Kinder. Beides gehört zum Kernbestand der Imago Turci.

Es sind ebensolche semantischen Mehrfachbesetzungen vermittels derer Ayrer die Bilder von den Türken vor dem inneren Auge der Rezipienten in Erscheinung treten,

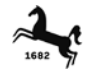


respektive imaginär >auftreten < lässt. Deshalb hebt auch die Handlungsebene immer wieder auf das Vor-Augen-Stellen ab - so wie in der dem Brudermord unmittelbar nachfolgenden Szene, in der Konstantin seinen ersten Auftritt hat.

\subsection{Inszenierte Augenzeugenschaft}

Konstantin berichtet seinen Getreuen, der junge[] Tyrannische[] Machumet habe sein Regiment blutig begonnen, nämlich seiner Mutter vor dem Gsicht / Ihren jungen Sohn hingericht (AD 2, S. 742,10-13). Den Rezipienten wird durch diese nachträgliche Erzählung die Position von (Augen-)Zeugen des Geschehens (Brudermord) zugewiesen, welche die Geschichte des Kaisers grundsätzlich beglaubigen könnten. Das Muster wiederholt sich auch an anderer Stelle. So gesteht einer der gepeinigten Griechen nach der grausamen Unterwerfung, er habe Von des Türcken schröcklichen Gschichtn zwar bislang viel gelesen und gehört (vgl. AD 2, S. 770,30-34, zit. 32), aber er habe das Gelesene und Gehörte nicht glauben wollen. Nun wird er selbst Zeuge dieses Leids, nur ist sein Leid für ihn so groß, dass es topisch unsagbar wird. Man kann die Türkengräuel weder aufschreiben noch einfach verbal artikulieren. Darum müssen sie ins Bild gesetzt werden. Die Figur formuliert dies ihrem Publikum gegenüber direkt aus: Als man nicht schreibn vnd sagen kan. / O lieben Christen, secht vns an! (AD 2, S. 771,1f.). Auch in dieser Weise bindet das Drama als mediales Dispositiv sein Publikum in die Konstruktion historischer Wahrhaftigkeit ein.

Ein weiteres Mittel der Vergegenwärtigung des historischen Geschehens ist der öffentliche Umgang mit der Türkengefahr, zu dem die Abgabe der Türkensteuer sowie der Aufruf zum regelmäßigen Türkengebet gehören: Diß alles man außruffen muß, / Das mans halt in der gantzen Stadt (AD 2, S. 744,28f.). Während das Fasten als Maßnahme gegen die Türkengefahr über die Narrenfigur dem Verlachen preisgegeben wird (vgl. AD 2, S. 744-747), bezieht das Drama deutlich Position für die monetäre Unterstützung des Verteidigungskampfes durch das Volk. Die Türken frohlocken nämlich ob des Geizes der reichen Bürger, die ihren Kaiser nicht zu unterstützen gedenken. Diese Haltung lässt das Stück als Indiz für den inneren Unfrieden unter den Christen erscheinen (vgl. AD 2, S. 756,7-15). Die Türken leiten aus der Uneinigkeit des Gegners ihren sicheren Erfolg ab: Das alles kompt nur vns zum besten. / Wölln sie jhr Geldt nicht hergeben, / So verlirn sie halt jhr Leben (AD 2, S. 756,17-19). Ayrer verbindet hier also das Politikum der Türkensteuer mit dem überkommenen Problemkomplex christlicher Discordia.

Das Mittel der Augenzeugenschaft verwendet Ayrer darüber hinaus vermittels der Inszenierung brieflicher Kommunikation zwischen dem Sultan und dem Papst, sowie der performativen Ausstellung der Dramen-Quelle, d.h. des Berichts Isidors. Zunächst erbittet Konstantin per Brief, der dem Papst vorgelesen wird, Unterstützung im Kampf gegen die Türken und ersucht ihn, seinen Boten Glauben zu schenken. Solchermaßen auf schriftlichem Wege legitimiert berichtet Phebus, einer der Boten Konstantins, dem Papst von der Situation in Griechenland (AD 2, S. 751,35). Bemerkenswerterweise begründet der Bote die prekäre Lage mit einem Brief, den Konstantin vom Sultan erhalten hat: 
O heiligster Herr, hochgemelt,

In Griechenland es übel steht;

Dann der groß Keiser Machumet

Vnserm Keiser Constantino

Ein Absagbrieff geschickt, laut also,

Daß er ju indem gantzen Land

Heimsuchen wöll mit Mord vnd brand

Vnd Constantinopel gewinnen.

(AD 2, S. 751,34-S. 752,5)

Der Brief dokumentiert nachträglich, was das Drama schon vorab mit dem Auftritt Machuments vorgeführt hat, so dass der Leser auch hier in die Position eines Augenzeugen versetzt wird, der für den Wahrheitsgehalt der Darstellung bürgen könnte. Selbst für die Quelle des Dramas, als welche im Eingang des Stücks der Bericht Isidors über die Einnahme Konstantinopels benannt worden war, findet dieses Verfahren Anwendung. Denn wenn der Kardinal seinen Auftritt hat und seinen eigenen Bericht verliest (vgl. AD 2, S. 778-780), haben sich die geschilderten Ereignisse längst vor dem (inneren) Augen des Publikums abgespielt.

\subsection{Vergegenwärtigung von Geschichte}

Die besondere mediale Pointe des Dramas besteht also wie gezeigt darin, dass es Geschichte ganz ausdrücklich vor Augen zu stellen sucht. Als Verfasser einer Reimchronik beherrscht Ayrer das Verfahren der historisch-chronikalischen Einordnung auch in seinem Drama. Er datiert das dargestellte Ereignis durch eine der Figuren im dritten Akt historisch genau:

Das Constantinopel gewunnen war,

Den neun vnd zwantzigsten May

Nach der Geburt JEsu CHRisti

Vierzehen hundert funfftzig drey

(AD 2, S. 782,5-8).

Nachdem der vierte Akt von der Begegnung des Türkenkaisers mit dem Narren und der schönen Hircavena handelt, wird mit der gleichen Genauigkeit der fünfte Akt nach einem Zeitsprung von etlich zwainzig Jahrn (AD 2, S. 795,4) eröffnet. Dazu tritt sogar eigens ein christlicher Gelehrter am Hof des Türkenkaisers auf. Dieser Gelehrte hat in Teutsch und Welschlanden / Auff vil hohen Schulen gestanden (AD 2, S. 794,17), er ist des Lateinischen und Griechischen mächtig und unterrichtet Machumets Sohn. Diese Figur steht für die Art, wie die historische Lehre durch das Drama enthüllt und vor Augen geführt wird. Im Stück weist sie auf den Verlust der Tugend hin, der am Türkenkaiser deutlich wird: Statt seine Pflicht als Herrscher zu erfüllen, lässt sich Machumet nur noch von den Possen Jahns unterhalten. Überdies ist er der Schönheit der gefangenen Hircavena vollständig verfallen. Der Witz des Narren und das Bild der Schönen haben den Türkenkaiser um den Verstand gebracht, so dass Sein Vernunfft will nicht geben raht (AD 2, S. 802,21).

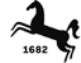


Diese im Drama am Türken vorgestellte Einschränkung der Urteilskraft bezieht sich zweifellos auch auf das Drama selbst. Sie enthält einen metapoetischen Hinweis auf die Gattungsmischung und ihre ästhetischen Folgen. Die Figur des Narren, der aus der Komödie stammt, und die der Hircavena, anhand der die Tragödie inszeniert wird, stehen schon im Stück für seine Wirkung auf den Rezpienten. Über den Türkenkaiser wird so das drohende Missverständnis des Türkendramas im Türkendrama inszeniert.

Machument hatte den Narren ausdrücklich zu dem Zweck an seinem Hof belassen, damit er Zu zeiten die lang weil vertreibn möge (AD 2, S. 793,3). Diese Unterhaltungsfunktion wird nachdrücklich hervorgehoben. Man könnte unter Anspielung auf Horaz sagen: Die delectatio ist von jeder utilitas abgekoppelt. Der Kurzweil dient dem Sultan auch seine Gefangene Hircavena, die er als Objekt seiner Begierde missbraucht. Die Schönheit der Christin verführt den Kaiser zu Müßiggang und Untugend. Die typische Ambivalenz des Türkenmotivs wird so bei Ayrer noch einmal deutlich, aber sie wird ausgerechnet durch eine Christin provoziert. Im letzten Drittel des Dramas ist der Türkenkaiser auch noch lüstern, erst damit steht er der Tugend direkt entgegen. Doch im Vexierbild des Türken kann das Bild der Untugend auch direkt wieder in ein Bild der Tugend umschlagen.

Dieser Umschlag wird durch ein historisches Argument herbeigeführt. Der christliche Lehrer des Sultansohnes spricht es aus. Wie er aus der Lektüre von Historien (AD 2, S. 794,34) weiß, besitzt die Genealogie des Türkenkaisers christliche Wurzeln. Dieser christliche Ursprung, der die Fähigkeit Machumets zur Tugend begründet, wird durch seine Wendung zum Laster verdeckt. Der Narr und die Schöne, also das komische und das tragische Element des Dramas, haben dieses Laster im Türkenkaiser hervorgebracht. Der abschließende Rat an den Herrscher zielt nun darauf, das Bild des Türken zu wenden. Wichtig für diese Wende ist der Umstand, dass der Sultan zunächst nicht durchgängig ein Despot ist, sondern auf seine Berater hört. Weil er sich beraten lässt und in seinem Handeln konsequent vorgeht, ist er - zu Ungunsten der uneinigen Christen - erfolgreich. Sein Berater Mustapha formuliert dies mit Blick auf den Fall Konstantinopels schon im Vorspiel über einen auffälligen Vergleich aus: Mit gutem rath, witz und bedacht, / Hat man Troja zu wegen bracht (AD 2, S. 740,4f.). Diese Bemerkung ist vor dem Hintergrund der historischen Diskussion über die mögliche Herkunft der Türken von den Trojanern aufschlussreich. ${ }^{36}$ Die historische Bildung des Autors Jacob Ayrer scheint hier zweifellos durch. Vor

\footnotetext{
36 Das Narrativ von der Troja-Deszendenz der Türken war schon im Mittelalter verbreitet und diente in verschiedensten Varianten der Identitätsstiftung und Herrschaftslegitimität (vgl. Borgolte, Michael: »Europas Geschichten und Troia. Der Mythos im Mittelalter«. In: Troia. Traum und Wirklichkeit [Ausstellungskatalog]. Stuttgart 2001, S. 190-230; Wolf, Kordula: Troja-Metamorphosen eines Mythos. Französische, englische und italienische Überlieferungen des 12. Jahrhunderts im Vergleich. Berlin 2009). Es gewann mit der Ausweitung des Osmanischen Reichs an Popularität. Man setzte sogar »die alten Trojaner (lat. Teucri) mit den Türken (Turci) in eins « (Gehrke, Hans Joachim: »Was heißt und zu welchem Ende studiert man intentionale Geschichte? Marathon und Troja als fundierende Mythen «. In: Gert Melville/KarlSiegbert Rehberg [Hg.]: Gründungsmythen, Genealogien, Memorialzeichen. Beiträge zur institutionellen Konstruktion von Kontinuität. Köln 2004, S. 21-36, hier S. 33) und die Einnahme von Byzanz kam einer Revanche an den Griechen gleich: Die vor langer Zeit aus Troja Vertriebenen seien zurückgekehrt, um sich zu rächen. Diese These, die Türken selbstbewusst vorbringen zu lassen, ist Teil ihrer Stilisierung und der Imago Turci (vgl. Ackermann [s. Anm. 1], S. 169-173).
} 
allem aber wird sie dann im Schlussbild ausgespielt. Es greift über den HircavenaStoff die Troja-Anspielung wieder auf und wendet auch sie neu.

In der letzten großen Szene des fünften Aktes lässt Machumet Hircavena noch einmal in ihrer Schönheit auftreten. Den Vorwurf, Von wegen der schönen Griechin (AD 2, S. 806,2) seine Herrschertugend verloren zu haben, überprüft er ganz praktisch. Denn ihr Auftreten bestätigt die Wirkung ihrer Schönheit einmal mehr. Die Räte, die den Türkenkaiser über seine Untugend aufgeklärt haben, werden umgehend von Hircavenas Anblick in den Bann geschlagen. Das anschauliche, praktische Experiment führt dazu, dass der Türkenkaiser seine Urteilskraft zurückgewinnt. Der Hoflehrer versieht Hircavenas Schönheit mit einem gelehrten Kommentar:

Fürwahr ich muss auch reden drein

Das Mensch daß ist die schönste worn

Auff Erden von eim Weib geborn,

Das ich muß warlich glaubn frey,

Die Helena auß Griechen sey

So schön nicht gwesen, alß die ist.

(AD 2, S. 806,27-32)

Damit ist das Urteil des Türkenkaisers gefällt und er tötet Hircavena. Die Szene ist kurz und drastisch, setzt aber einen anspielungsreichen Schlusspunkt des Dramas. Der gelehrte Vergleich liefert hierfür den letzten Hinweis: So wie die erfolgreiche Eroberung Konstantinopels schon zu Beginn des Dramas mit der Eroberung Trojas verglichen wurde, so bildet jetzt auch der Vergleich mit Helena eine Schlüsselstelle, aus der das Tugendproblem des Türkenkaisers lesbar wird.

Schon in der Troja-Überlieferung steht hinter dem Namen Helenas stets das Parisurteil, in dem die Schönheit die Urteilsfähigkeit des Urteilenden betörte, so dass dieser die Gaben der nützlichen Tugenden zugunsten der Liebe ausschlug. Das Parisurteil der Schlussszene steht damit paradigmatisch für die getrübte Urteilsfähigkeit. Das Bild der schönen Griechin betörte den Türkenkaiser, dessen trojanische Herkunft damit zweifellos als Konnotation wieder mit im Raum steht. Aber die These von der trojanischen Herkunft der Türken wird hier vom gelehrten Rezipienten der Szene, der im Drama selbst vorkommt, durch eine christliche Lesart überschrieben. Diese Lesart gilt dem Experiment mit der Schönheit, das der Kaiser als Spiel im Spiel selbst auf die Bühne gebracht hat. Weil die Figur des Türken die Wirkung des Bildes auf seine Ratgeber durchschaut, gewinnt er seine Urteilskraft zurück. Der Gelehrte liefert dem Rezipienten des Stücks dazu den Lektüreschlüssel, der dem Wandel des Türkenbildes auf der Bühne gilt.

\subsection{Das Drama als Vexierspiel}

Selbst der Mord an der tugendhaften Christin Hircavena vereindeutigt Machumet nicht als grausamen Tyrannen, ist sie doch in ihrer Schönheit auch eine Verführerin zur Untugend. Demgegenüber kennzeichnet den Türkensultan durchaus eine gewisse Tugendhaftigkeit. Weil er in seiner Genealogie auch christliche Wurzeln hat, kann seine Grausamkeit in Tugend umschlagen; er gewinnt seine Urteilsfähigkeit zurück und ist damit, in seiner Grausamkeit, doch noch vorbildlicher Herrscher. So 
wird, anders als der Dramenbeginn vermuten lässt, die Türkenfigur als Vexierbild inszeniert.

Aber auch das Drama selbst changiert. Es spielt zwischen Tragödie und Komödie. Nach dem grausamen, tragischen Tod Hircavenas verlässt der Narr laut schreiend die Bühne und meldet sich so noch einmal effektvoll und vernehmlich zu Wort. Die Geste des Narren ist theatralisch, sie ruft damit am Ende nochmals das mediale Dispositiv des Theaters auf, wirksam im Rahmen eines Lesedramas. Das Theaterstück spielt in der Imagination des Lesers. Die Bühne, auf der die Figuren zu agieren scheinen, ist der Text des Dramas.

Über den medialen Status belehrt in der Nachrede der Ehrnhold: Dreh- und Angelpunkt dieses Vexierspiels ist das Bild des Türken. An ihm exemplifizieren sich die Laster und Tugenden, über die sich die narrative Basis des Dramas ausbildet. Denn sein Bild vollzieht einen Dreischritt: vom grausamen Eroberer Konstantinopels, der von der Schönheit und der Unterhaltungskunst um den Verstand gebracht wird, der aber schließlich seine Urteilsfähigkeit und damit seine Tugenden zurückerlangt. Vom Türkenbild hängt damit die Erzählstruktur des Dramas ab. Aber die Geschichte mit ihrer narrativen Struktur ist dazu da, das Bild des Türken vor den Augen des Rezipienten lebendig werden zu lassen. Das Drama Ayrers spielt so etwas vor, aber es spielt zugleich mit dem Rezipienten. Auch hier beginnt das Vexierspiel erneut. Im Bild des Türken hat es sein Modell.

\section{Fazit}

Das für die Turcica spezifische Spannungsverhältnis zwischen Realität und Fiktion inszeniert Ayrers Machument-Drama in einer ganz eigenen Verknüpfung von historischem Geschehen, literarischer Tradition und tradierten Topoi, die er zu einem neuen Narrativ kombiniert. So bedient und überbietet sein Stück zunächst die gängigen anti-osmanischen Topoi, wodurch sich an diesem Fall ganz unmittelbar die Verdoppelung der performativen Qualität der Turcica im Drama zeigt, also die für die Türkendramen charakteristische Inszenierung der Inszenierung. Bei Ayrer kommt jedoch hinzu, dass er vorgibt, die historischen Quellen selbst in ihrer Medialität auf die Bühne zu stellen. Bild und Brief werden in Dialog und Handlung überführt, und die Pointe des Verfahrens ist es schließlich, den Rezipierenden die Position von Augenzeugen und potentiellen Bürgen der Geschichte zuzuweisen und ihn so in die Wirklichkeit des Dramas immergieren zu lassen.

Dieser immersive Effekt hat eine Entsprechung auf medialer Ebene insofern sich Ayrers Drama als Theater ausgibt. Die schriftliche Inszenierung des Theaterspiels veranlasst die Rezipienten, den performativen Prozess der Aufführung vor ihrem inneren Auge abzuspielen, das aufgeführte Drama als gedanklich vorgestelltes Bühnenstück zu realisieren, ganz so wie es das Titelblatt des Opus Thaeatricum für Ayrers Dramen als literarische Monumente und ihre spezifische historische Ästhetik verspricht.

Der Medialisierungsprozess des Türkendramas erreicht damit am Ende des 16. Jahrhunderts einen Höhepunkt. Analog zu den kulturellen Transformationsprozessen des Türkenbildes macht Ayrer mit Hilfe des Türkenbildes die medialen 
Transformationsprozesse des Dramas deutlich. Die medialen Dispositive Theater und Drama werden nun autopoetisch wirksam. So klingt mit Ayrer das Türkendrama des 16. Jahrhunderts in einer poetologischen Überhöhung der polyphonen Imagines Turci aus.

Funding Open Access funding enabled and organized by Projekt DEAL.

Open Access Dieser Artikel wird unter der Creative Commons Namensnennung 4.0 International Lizenz veröffentlicht, welche die Nutzung, Vervielfältigung, Bearbeitung, Verbreitung und Wiedergabe in jeglichem Medium und Format erlaubt, sofern Sie den/die ursprünglichen Autor(en) und die Quelle ordnungsgemäß nennen, einen Link zur Creative Commons Lizenz beifügen und angeben, ob Änderungen vorgenommen wurden.

Die in diesem Artikel enthaltenen Bilder und sonstiges Drittmaterial unterliegen ebenfalls der genannten Creative Commons Lizenz, sofern sich aus der Abbildungslegende nichts anderes ergibt. Sofern das betreffende Material nicht unter der genannten Creative Commons Lizenz steht und die betreffende Handlung nicht nach gesetzlichen Vorschriften erlaubt ist, ist für die oben aufgeführten Weiterverwendungen des Materials die Einwilligung des jeweiligen Rechteinhabers einzuholen.

Weitere Details zur Lizenz entnehmen Sie bitte der Lizenzinformation auf http://creativecommons.org/ licenses/by/4.0/deed.de. 